\title{
Geographical Distribution of Criminal Offenses in Sendai, Japan
}

\author{
Katsuo KUWAJIMA*
}

\begin{abstract}
Recently, the number of criminal offenses occuring in most cities in Japan has been gradually increasing. The main purpose of this paper is to clarify the regionality and distribution of specific crimes (shoplifting, house burglary, office robbery, and assualt and battery) in Sendai. The results are summarized as follows: 1) In general, Sendai conforms to the archetypal pattern of having a low rate of crime in the suburbs and steadily increasing crime rates reaching a peak in the inner city and the CBD. 2) Location of the highest crime rate depends on the type of offense and did not always occur in the CBD. 3) There is a close relationship between criminal offenses and the areal differentiation of urban function. Depending on the differing arrangement of urban establishments, the geographical distribution of crime changes.
\end{abstract}

\section{Introduction}

In recent years, the number of criminal offenses occurring in Sendai, the capital of Miyagi Prefecture in Northeastern Honshu, has been gradually increasing. For example, the number of reported offenses increased from 8459 in 1973 to 8918 in 1983. The number of criminal offenses reported in Miyagi Prefecture has increased roughly in proportion to population growth. Such an increase is a general trend throughout Japan, but there have been few detailed geographical studies of crime in this country.

In this paper, the areal distribution of criminal offenses in 1973 and 1983 are compared and discussed. Additionally, the regionality and distribution of specific crimes during the same period is described. The specific crimes studied were: shoplifting, house burglary, office robbery, and assualt and battery. These four were selected because of their comparatively high frequency of occurance. Police box territories are classified into one of four types based on their location in the zones of city growth (as shown in Fig.1). The distribution of police boxes and night population in 1983 is shown in Fig. 2.

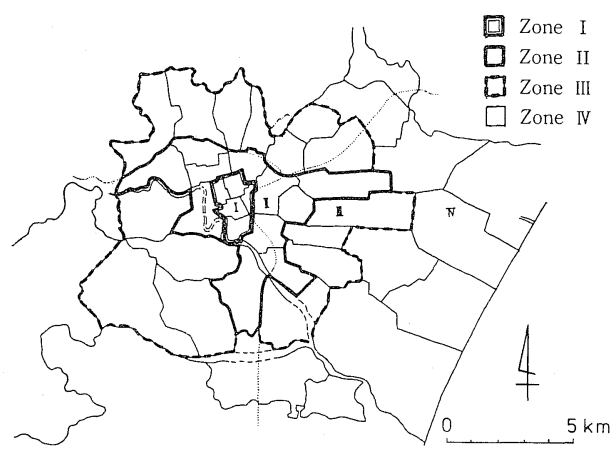

Fig. 1 Zones of city

Zone I: CBD Zone II : Old built-up area Zone III : New built-up area (after World War II) Zone IV : Suburbs

\footnotetext{
* Tohoku Fukushi University
} 


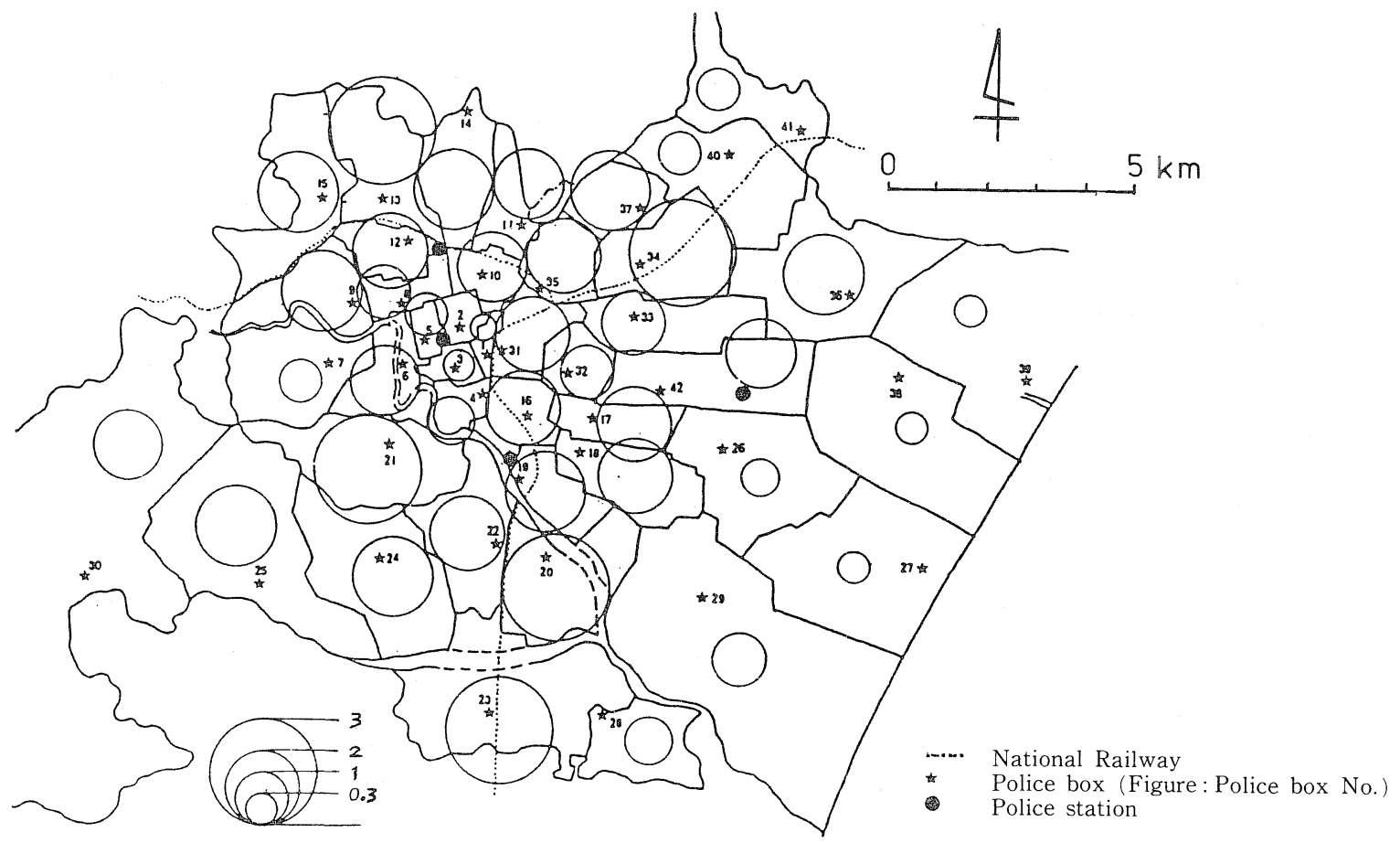

Night population

(10,000 population)

Fig. 2 The distribution of police boxes and population

\section{Crime distribution}

\section{Shoplifting}

Shoplifting is the most commonly reported crime, representing $22 \%$ of all criminal offenses reported in 1973 and in 1983. In 1973, shoplifting offenses were concentrated in the CBD (Zone I). By 1983, however, two distinct patterns emerged: (1) a concentration in the CBD similar to that of 1973 and (2) dispersion in the residential area (Zone III). (Fig. 3) In 1973 more than 84\% of all shoplifting offenses occurred in the CBD, but in 1983 the percentage had fallen to under $65 \%$ in that area. Correspondingly, shoplifting in the residential area (Zone III) increased from 3.2\% to $22.2 \%$ (Fig. 4).
The primary reason for the increase of shoplifting in residential areas is the establishment of large branch department stores and supermarkets in the suburbs. Since approximately $80 \%$ of all shoplifting offenses occur in department stores and supermarkets, the relationship between incidents of shoplifting and floor space of big stores (500 $\mathrm{m}^{2}$ and up) was analyzed (Fig. 5). The correlation coefficient of 0.922 indicates a close relationship between the two factors.

\section{House burglary}

The number of house burglaries reported in 1973 was 831 ; by 1983 the number had increased only slightly to 851 . However, the crime distribution pattern shifted remarkably during the decade. Crime distribution in the $\mathrm{CBD}$ and the 
Kuwajima, K.: Geographical distribution of criminal offenses in Sendai, Japan
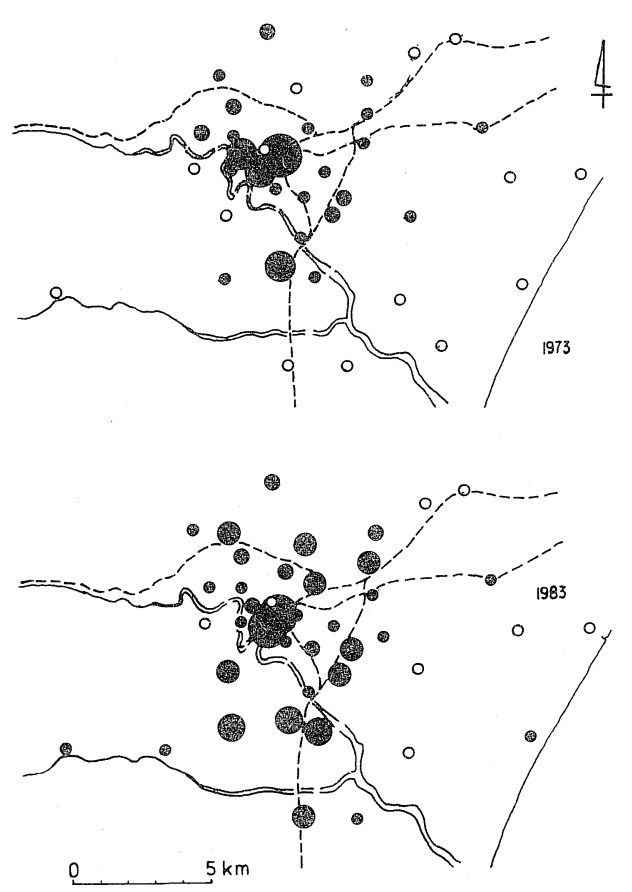

Number of offenses 0 o
$30 \sim 49$
$50 \sim 99$
$100 \sim 499$

- $-\infty-$ National railway

Fig. 3 Distribution of shoplifting offences by police box territory

suburbs were essentially unchanged, but the distribution in the old built up area (Zone II) and the new built area (Zone III) changed considerably. (Fig. 6) In 1973 the peak number of crimes were reported in Zone II, but in 1983 the peak had shifted to Zone III, the newly built up area surrounding the second zone (Fig. 7). This shift can be attributed to the dramatic increase of housing in outlying districts and the drastic decline of private residences in the CBD. However, the correlation coefficient between night population and number of house burglaries was only 0.528 in 1983. This low value occurs because the crime generally takes place during the day time when the family is not at home and the door is left unlocked.

3 Office Robbery

Although the distribution of office robberies
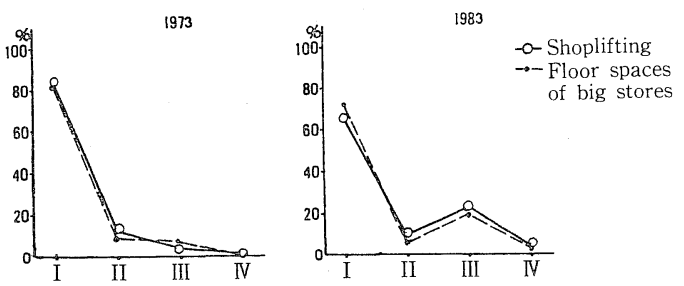

I : CBD II : Old built-up area

III : New built-up area IV : Suburbs

Fig. 4 Shopliftirg offenses and the floor space of big stores in each zone
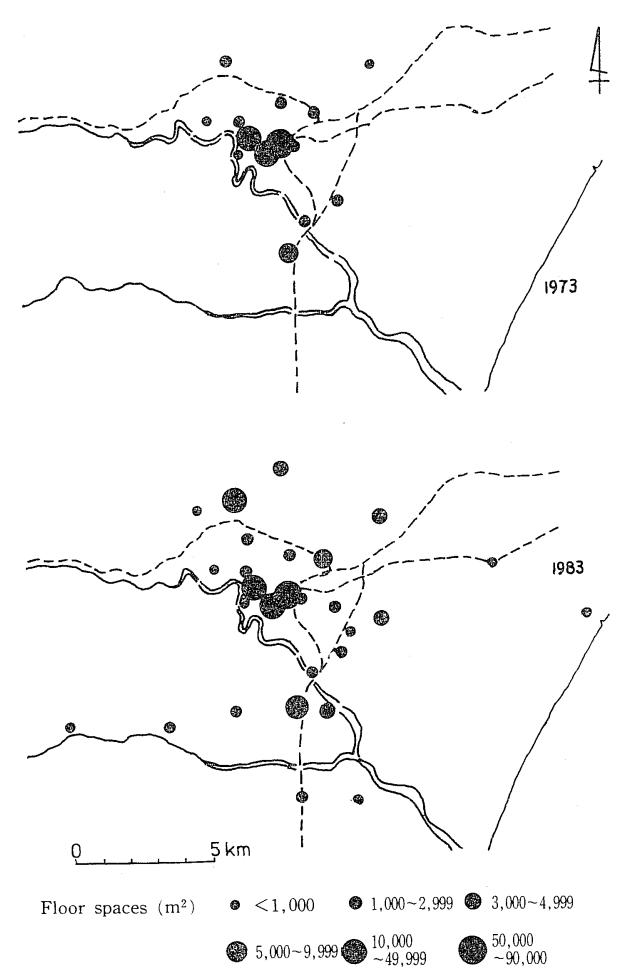

Fig. 5 Distribution of stores with large floor spaces by police box territory

showed a concentration in the CBD in 1973, by 1983 a large number of robberies were reported in the industrial estates of the newly built up area; in fact, the peak number of offenses shifted to Zone III (Fig. 8, 9). Incidence of office robberies is closely related to areal differentiation of the urban function. Calculating the correlation coefficient between number of establishments and 

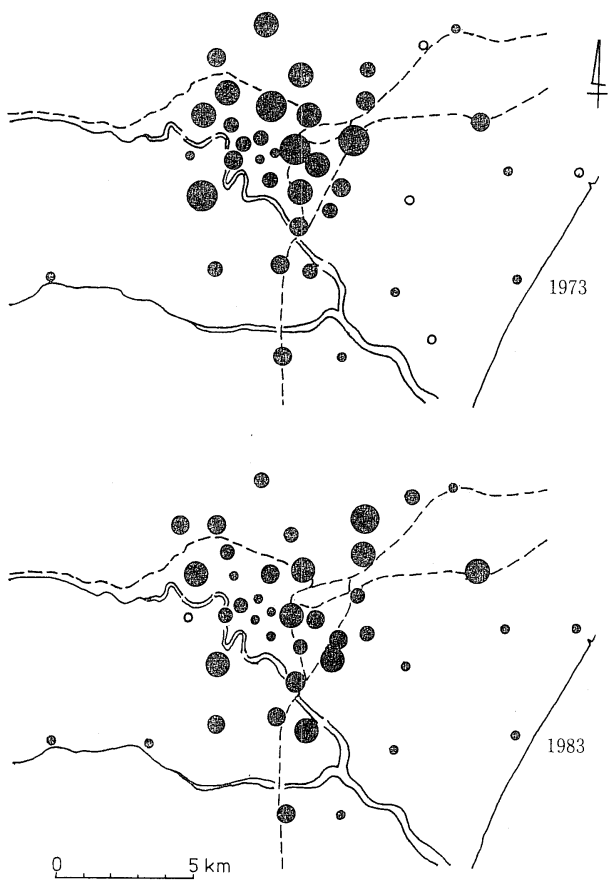

Number of offenses $\circ 0 \quad 0 \quad 1 \sim 9$ 10 19

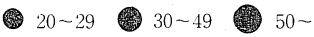

Fig. 6 Distribution of house burglaries by police box territory
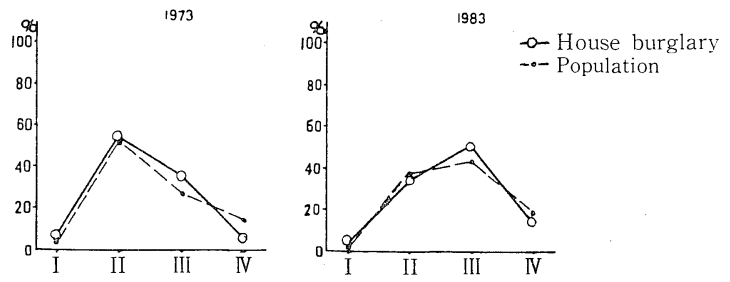

Fig. 7 House burglaries and population in each zone

the number of crimes, a value of 0.431 was obtained. The reason for such a surprisingly low value is that while office robberies decreased in the crowded CBD, they greatly increased in the more sparsely populated industrial parks in the suburbs. This is due to the fact that many older establishments in the CBD have developed welldevised crime prevention systems while some of the newer establishments in the suburbs still have rather poor systems.
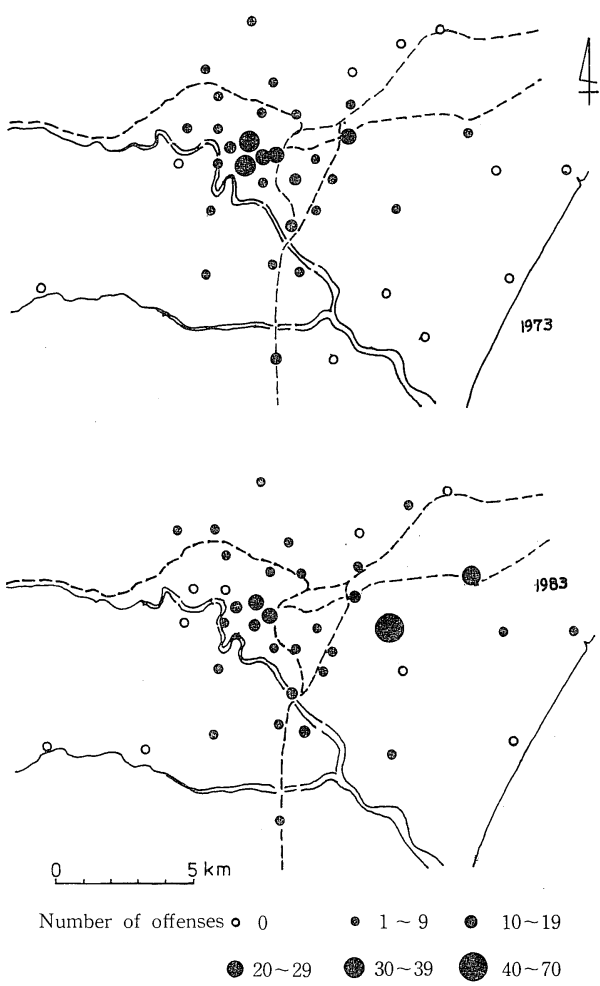

Fig. 8 Distribution of office robberies by police box territory

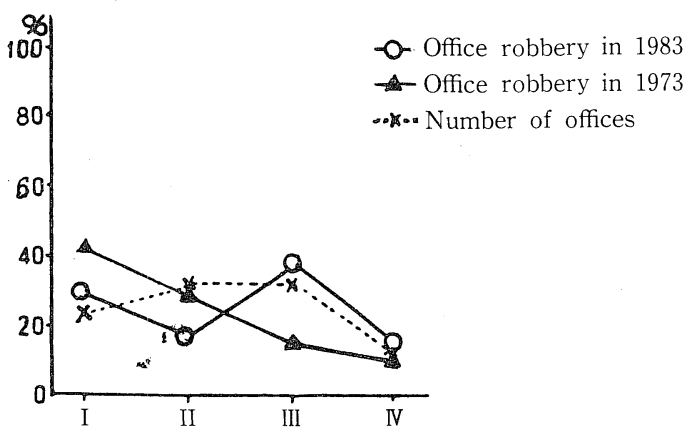

Fig. 9 Office robberies and offices in each zone

\section{Assualt and battery}

During the decade, incidents of assualt and battery decreased significantly, from 395 cases in 1973 to 222 cases in 1983. As shown in Figs. 10 and 11 , this crime was mainly concentrated in the CBD, 45\% of the total in 1973 and 57\% in 1983. Since gangsters account for much of the reported 

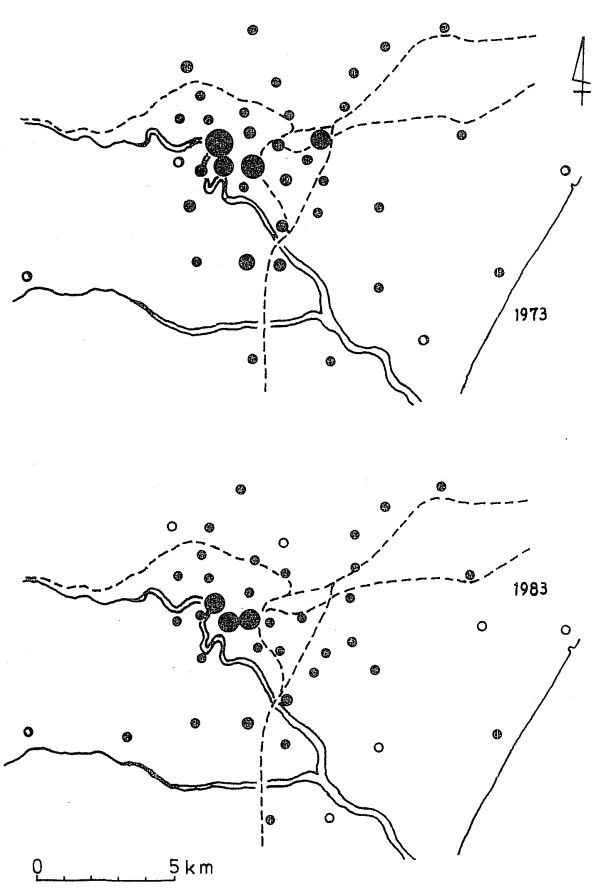

Number of offenses $\circ 0 \quad 1 \sim 10 \quad 10 \sim 19$

$$
\text { 궁 } 30 \sim 29 \text { 30 } 30 \sim 70
$$

Fig. 10 Distribution of assault and battery cases by police box territory

total (40\% in 1982), stricter control of the gangs by police has reduced the number of reported offenses.

\section{Regionality and crime rate distribution.}

Currently most metropolises in the USA conform to the archetypal pattern identified in Chicago (Shaw, 1929), i.e., low crime rates in the suburbs and steadily increasing crime rates that reach a peak in the inner city and $\mathrm{CBD}$. The crime rate in high crime districts perpetuates itself as residents learn criminal skills from each other.

Similarly, Sendai's CBD has the highest crime rate and its suburbs the lowest: Crime rate is based on number of crimes per 1000/population of the police box territory (Fig. 12). However, the high crime district of Sendai's CBD is not a fixed

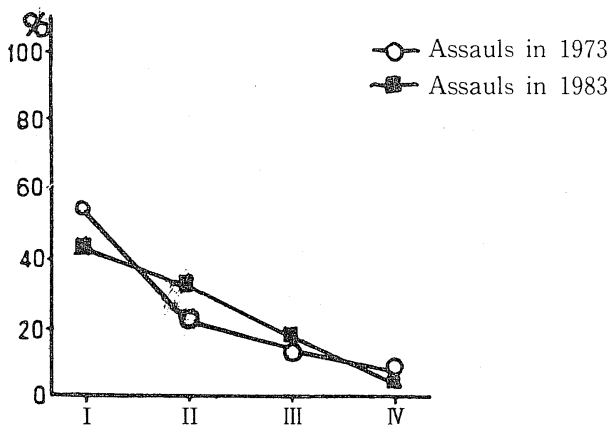

Fig. 11 Assaults in each zone

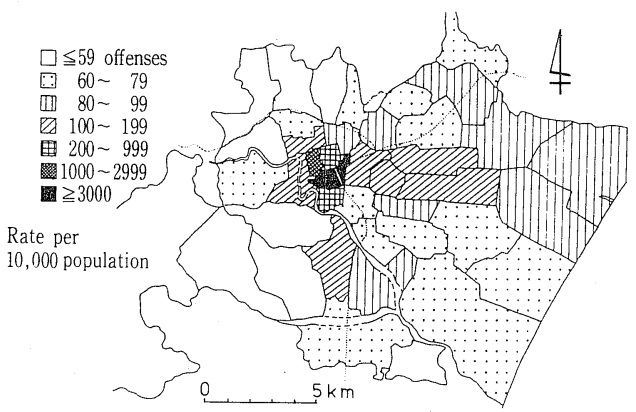

Fig. 12 The crime rate by police box territory

criminal area as, for example, the slums of an American city. Most of the criminals there, in fact, actually come from other regions such as the suburbs or even different towns. Further, the crime rate of specific offenses depends on the area, i.e., the areal differentiation of the urban function. Shoplifting, for instance, occurs in main shopping streets of the CBD and shopping centers in the suburbs. The areal distribution of the crime rate is concentric with the three zones around the $\mathrm{CBD}$, and the highest rate districts are Zones I and III (Fig. 13).

The relationship between crime rate and the areal differentiation of urban function is also seen in the distribution of office robberies (Fig. 14). That is, high crime rates occur in the CBD and the industrial estates of Zone III. The highest crime rate of house burglaries is found in the eastern 


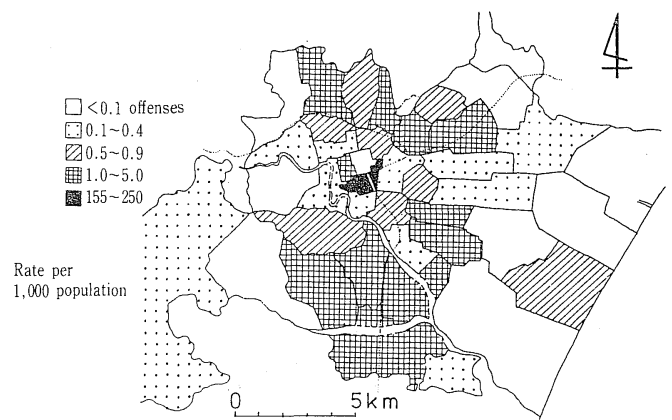

Fig. 13 The rate of shoplifting offenses by police box territory

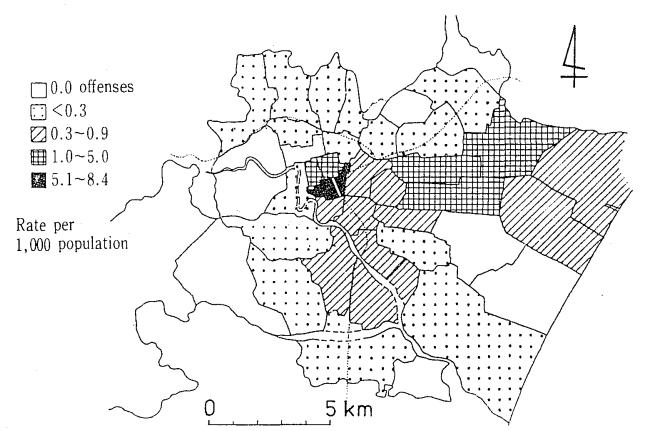

Fig. 14 The rate of office robberies by police box territory

section of the CBD and the northeastern part of the residential area (Fig. 15). There is a residential section containing some blocks of low income families in the second area, and some habitual criminals are found among those families.

\section{Conclusions}

1) In general, Sendai conforms to the archetypal pattern of having a low rate of crime in the suburbs and steadily increasing crime rates reaching a peak in the inner city and the CBD.

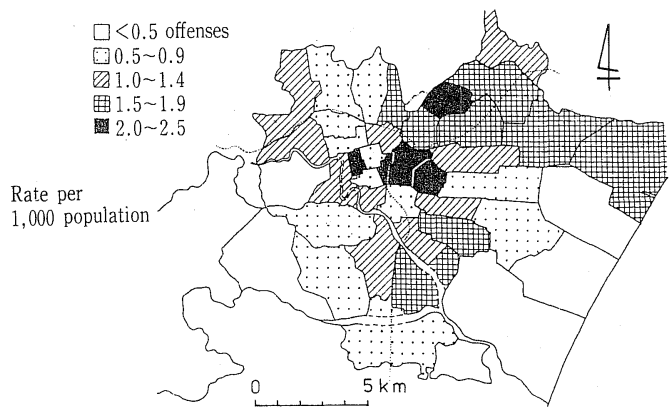

Fig. 15 The rate of house burglaries by police box territory

2) Location of the highest crime rate depends on the type of offense and did not always occur in the $\mathrm{CBD}$, viz. the crime rate distibution of shoplifting, house burglaries, and office robberies.

3) There is a close relationship between criminal offenses and the areal differentiation of urban function. Depending on the differing arrangement of urban establishments, the geographical distribution of crime changes.

4) In recent years, the crime rate in Sendai is gradually increasing with the exception of violent offenses.

\section{References}

Ito, S. (ed.) (1982): City and Crime, Toyokeizaishinposha.

Knox, P. (1982): Urban Social Geography-An Introduction-, Longman, London and New York.

The Police Headquarters of Miyagi Prefecture $(1973,1983)$ : Statistical Table of Crimes.

(accepted February 19, 1985)

\section{都 市と 犯 罪 一仙台市の例一}

\section{桑 島 勝 雄}

